\title{
Determination of parathion in biological fluids by means of direct solid-phase microextraction
}

\author{
E. Gallardo • M. Barroso • C. Margalho • A. Cruz • \\ D. N. Vieira $\cdot$ M. López-Rivadulla
}

Received: 29 March 2006 / Revised: 4 July 2006 / Accepted: 4 August 2006 / Published online: 5 September 2006

(C) Springer-Verlag 2006

\begin{abstract}
A new and simple procedure for the determination of parathion in human whole blood and urine using direct immersion (DI) solid-phase microextraction (SPME) and gas chromatography/mass spectrometry (GC/MS) is presented. This technique was developed using only $100 \mu \mathrm{L}$ of sample, and ethion was used as internal standard (IS). A $65-\mu \mathrm{m}$ Carbowax/divinylbenzene (CW/DVB) SPME fibre was selected for sampling, and the main parameters affecting the SPME process such as extraction temperature, adsorption and desorption time, salt addition, agitation and $\mathrm{pH}$ effect were optimized to enhance the sensitivity of the method. This optimization was also performed to allow the qualitative determination of parathion's main metabolite, paraoxon, in blood. The limits of detection and quantitation for parathion were 3 and $10 \mathrm{ng} / \mathrm{mL}$ for urine and 25 and $50 \mathrm{ng} / \mathrm{mL}$ for blood, respectively. For paraoxon, the limit of detection was $50 \mathrm{ng} / \mathrm{mL}$ in blood. The method showed linearity between the LOQ and $50 \mu \mathrm{g} / \mathrm{mL}$ for both matrices, with correlation coefficients ranging from 0.9954 to 0.9999 . Precision and accuracy were in conformity with the criteria normally accepted in bioanalytical method validation. The mean absolute recoveries were $35.1 \%$ for urine and $6.7 \%$ for blood. Other parameters such as dilution of sample and stability were also validated. Its simplicity and the fact that only $100 \mu \mathrm{L}$ of sample is required to accomplish the analysis
\end{abstract}

E. Gallardo $(\bowtie) \cdot$ A. Cruz $\cdot$ M. López-Rivadulla

Instituto de Medicina Legal, Servicio de Toxicología Forense,

Universidad de Santiago de Compostela,

San Francisco s/n,

15782 Santiago de Compostela, Spain

e-mail: gallardoeugenia@hotmail.com

M. Barroso $\cdot$ C. Margalho $\cdot$ D. N. Vieira

Instituto Nacional de Medicina Legal,

Delegação de Coimbra, Largo da Sé Nova,

3000-213 Coimbra, Portugal make this method useful in forensic toxicology laboratories to determine this compound in intoxications, and it can be considered an alternative to other methods normally used for the determination of this compound in biological media.

Keywords Direct immersion solid-phase microextraction . Parathion · Whole blood · Urine

\section{Introduction}

Parathion [O,O-diethyl $O$-(4-nitrophenyl)phosphorothioate] is an organophosphorous pesticide of very high mammalian toxicity [1], and was synthesized by Schrader in the 1940s [2]. It acts by the irreversible inhibition of cholinesterases, which are responsible for hydrolysing, and thereby deactivating, the neurotransmitter acetylcholine [3, 4]. It may be absorbed through the skin, by inhalation and via the gastrointestinal tract. After absorption it is rapidly metabolized to paraoxon, in which the sulfur atom is replaced by oxygen. Both compounds are rapidly hydrolysed by plasma and tissue esterases to produce diethylthiophosphoric acid (DETP), diethylphosphoric acid (DEP) and $p$-nitrophenol. These products are largely excreted in urine and account for the majority of a dose of parathion; however, the parent compound is also excreted in its unchanged form [5].

Intoxication symptoms are similar to those produced by other cholinesterase inhibitors and include respiratory difficulty, excessive salivation, miosis, nausea, vomiting, muscle weakness and paralysis [6]. Toxic levels in plasma are reported to be in the range of 0.01 to $0.08 \mu \mathrm{g} / \mathrm{mL}$ [6].

Several methodologies have been developed for sample preparation prior to analysis of parathion in biological or environmental samples [7-10] and these usually involve time- and solvent-consuming techniques. Solid-phase microextraction (SPME), a rapid and simple sampling 
technique developed by Arthur and Pawliszyn in the early 1990s at the University of Waterloo (Ontario, Canada), can provide an alternative to those methods [11]. In fact, the sampling, extraction, concentration and sample introduction steps are combined into a single uninterrupted process, which results in high sample throughput [12]. SPME has been successfully applied for the determination of pesticides in environmental samples [13, 14], food [15-17] and biological samples [18-23]. Only three papers [24-26] describe the determination of parathion in biological samples by means of SPME, using the headspace sampling technique. However, to the best of our knowledge, the use of the direct immersion approach to determine parathion in this kind of sample has not been published in the literature.

This paper describes a new method based on direct immersion SPME combined with gas chromatography/mass spectrometry to determine parathion in blood and urine, using only $0.1 \mathrm{~mL}$ of sample.

\section{Experimental}

Reagents

Analytical standards, parathion and paraoxon were purchased from Riedel-de Haën (Seelze, Germany), and ethion (internal standard, IS), an organophosphorous insecticide not commercially available in Portugal, was obtained from Polyscience Corp. (Niles, IL, USA). All pesticide standards were of $98-99 \%$ purity.

Methanol (HPLC grade), phosphoric acid, sodium hydrogenphosphate and sodium chloride (analytical grade) were obtained from Merck Co (Darmstadt, Germany).

Stock standard solutions at $1,000 \mu \mathrm{g} / \mathrm{mL}$ for each compound were prepared in methanol and stored at $-20{ }^{\circ} \mathrm{C}$ in the dark. The analytes were stable under these conditions for at least 6 months. Subsequently working solutions at 100,10 and $1 \mu \mathrm{g} / \mathrm{mL}$ for parathion and paraoxon, and at $100 \mu \mathrm{g} / \mathrm{mL}$ for ethion, were prepared by appropriate dilution of the stock solutions with methanol. These solutions were stored protected from light at $4{ }^{\circ} \mathrm{C}$.

Phosphate buffer solutions $(0.07 \mathrm{M})$ were prepared by mixing solutions of phosphoric acid and sodium hydrogenphosphate in variable proportions, according to the desired $\mathrm{pH}[27]$.

\section{Biological samples}

Fresh human blood was obtained from the excess supplies of the Portuguese Institute of Blood (outdated transfusions), preserved with citrate phosphate dextrose (1:7), and was stored at $-20{ }^{\circ} \mathrm{C}$ until analysis. Urine specimens were obtained from healthy supposed non-exposed subjects (laboratory personnel).

Instrumentation

The SPME device for manual extraction and the coated fibres, $100-\mu \mathrm{m}$ polydimethylsiloxane (PDMS) and $65-\mu \mathrm{m}$ Carbowax/divinylbenzene (CW/DVB), were purchased from Supelco (Bellefonte, PA, USA). Before the first use, new fibres were conditioned as recommended by the manufacturer by heating them in the injector port of the chromatographic system for $30 \mathrm{~min}$, at $250{ }^{\circ} \mathrm{C}$ for PDMS and $220^{\circ} \mathrm{C}$ for $\mathrm{CW} / \mathrm{DVB}$ fibres.

Chromatographic analysis was performed using an HP 6890 gas chromatograph equipped with a model 5973 mass selective detector (Hewlett-Packard, Waldbronn, Germany). A capillary column $(12 \mathrm{~m} \times 0.25$-mm I.D., $0.25-\mu \mathrm{m}$ film thickness) packed with 5\% phenylmethylsiloxane (Ultra 2), supplied by J \& W Scientific (Folsom, CA, USA), was used.

Chromatographic conditions were as follows: initial oven temperature was $100{ }^{\circ} \mathrm{C}$ for $2 \mathrm{~min}$, which was increased by $10{ }^{\circ} \mathrm{C} / \mathrm{min}$ to $200{ }^{\circ} \mathrm{C}$, held for $1 \mathrm{~min}$, and finally elevated by $24{ }^{\circ} \mathrm{C} / \mathrm{min}$ to $270{ }^{\circ} \mathrm{C}$, kept constant for $2 \mathrm{~min}$. The temperatures of the injection port and detector were set to 240 and $280{ }^{\circ} \mathrm{C}$, respectively. Splitless injection mode was adopted, and the carrier gas was helium at a constant flow rate of $1 \mathrm{~mL} / \mathrm{min}$. The mass spectrometer was operated with a filament current of $300 \mu \mathrm{A}$ and an electron energy of $70 \mathrm{eV}$ in the electron impact (EI) mode. Quantitation was done in the selected ion monitoring (SIM) mode, and the ions were monitored at $\mathrm{m} / \mathrm{z} 109,139$ and 186 for parathion, at $m / z 109,149,275$ for paraoxon, and at $\mathrm{m} / \mathrm{z} 231,153$ and 125 for ethion: in each case the quantitation ion was at $\mathrm{m} / \mathrm{z} 109$.

The retention times were $11.10,11.80$ and 14.48 min for paraoxon, parathion and IS, respectively, obtaining a good separation of all compounds.

Extraction procedures

\section{Blood}

For sample preparation, $10 \mu \mathrm{L}$ IS $(100 \mu \mathrm{g} / \mathrm{mL})$ was added to $100 \mu \mathrm{L}$ blood. A final volume of $1 \mathrm{~mL}$ was obtained after appropriate dilution with deionised water. The sample was vortex-mixed for $30 \mathrm{~s}$, and the CW/DVB-coated fibre was directly immersed in it for $60 \mathrm{~min}$ at $60{ }^{\circ} \mathrm{C}$, without stirring. After extraction the fibre was retracted and washed by immersion in deionised water for $5 \mathrm{~s}$, after which it was thermally desorbed in the injector port of the GC for $1 \mathrm{~min}$ at $240{ }^{\circ} \mathrm{C}$. 


\section{Urine}

The procedure adopted to extract urine samples was similar to that of the blood, except that the extraction temperature was $90{ }^{\circ} \mathrm{C}$, and the washing step prior to desorption was omitted.

\section{Results and discussion}

\section{SPME optimization}

Before the application of the extraction technique to the samples, several experiments with spiked blood and urine samples $(1 \mu \mathrm{g} / \mathrm{mL})$ were carried out in order to select the optimum conditions for the extraction process. Each experiment was assayed thrice and individually for each selected pesticide, including IS, in each particular matrix. It should be stated that all the parameters related to paraoxon were only optimized for blood samples, because this metabolite is normally not detected in urine [5].

The optimized parameters were type of fibre coating, adsorption and desorption time, extraction temperature, agitation, salt addition and $\mathrm{pH}$ effect. Because SPME is an equilibrium process, rather than exhaustive [28], this systematic optimization of the experimental procedure was deemed necessary to achieve higher yields of the analytes and enhance method sensitivity.

The first parameter studied was the type of fibre coating. Two types of fibre coating were assayed: $100-\mu \mathrm{m}$ PDMS and $65-\mu \mathrm{m}$ CW/DVB. Peak areas obtained with each fibre were compared, and the CW/DVB fibre was chosen because it extracted 2 and 3 times the amount of parathion than the PDMS fibre in urine and blood, respectively.

In SPME the extraction involves the partitioning of the analytes between the matrix and fibre coating [29]. Therefore, the optimization of the contact time between these two phases is crucial to enhance method sensitivity.
To find the best adsorption time, spiked blood and urine samples were extracted during several controlled times $(1,5,10,15,25,35,40,60,90$ and $180 \mathrm{~min})$. After each extraction, the fibre was desorbed for $3 \mathrm{~min}$ at $240{ }^{\circ} \mathrm{C}$ in the injector port of the GC. The area counts were plotted against the extraction time (Fig. 1). We observed an increase in the extraction yield with the increase in the extraction time. Equilibrium was not reached by using these extraction times, and $180 \mathrm{~min}$ yielded the highest peak areas. However, the selected time for adsorption was not $180 \mathrm{~min}$, as it would waste the aim of a rapid method; a good compromise between acceptable sensitivity and extraction time therefore had to be established. The selected adsorption time was $60 \mathrm{~min}$ for both matrices.

This is possible because SPME is an equilibrium process, as stated above. However, equilibrium is not a prerequisite for a quantitative method. In fact, the equilibrium time is independent of the analyte concentration in the sample. On the other hand, the absolute amount of analyte extracted at a given time is linearly proportional to its concentration [30]. In this way, quantitation can be performed precisely and accurately, as long as the extraction time is the same for calibrators and samples.

The optimization of desorption time aims at achieving the quantitative desorption of the analytes. On the other hand, and because a single coated fibre is designed to last for several extraction/desorption cycles, the possibility of carry-over of analytes is an important issue that must be excluded during method optimization. Several desorption times $(1,2,3,4$ and $6 \mathrm{~min})$ and two different injector temperatures $\left(220\right.$ and $\left.240{ }^{\circ} \mathrm{C}\right)$ were tested. On the basis of peak area evaluation, the best desorption conditions were found to be $1 \mathrm{~min}$ at $240{ }^{\circ} \mathrm{C}$. The carry-over of analytes was excluded by analysis of blood and urine samples spiked with high amounts of the compounds $(100 \mu \mathrm{g} / \mathrm{mL})$. After the chromatographic run, the fibre was immediately subjected to the same desorption conditions. No peaks were
Fig. 1 Adsorption time profile for parathion, paraoxon and IS in blood and urine samples

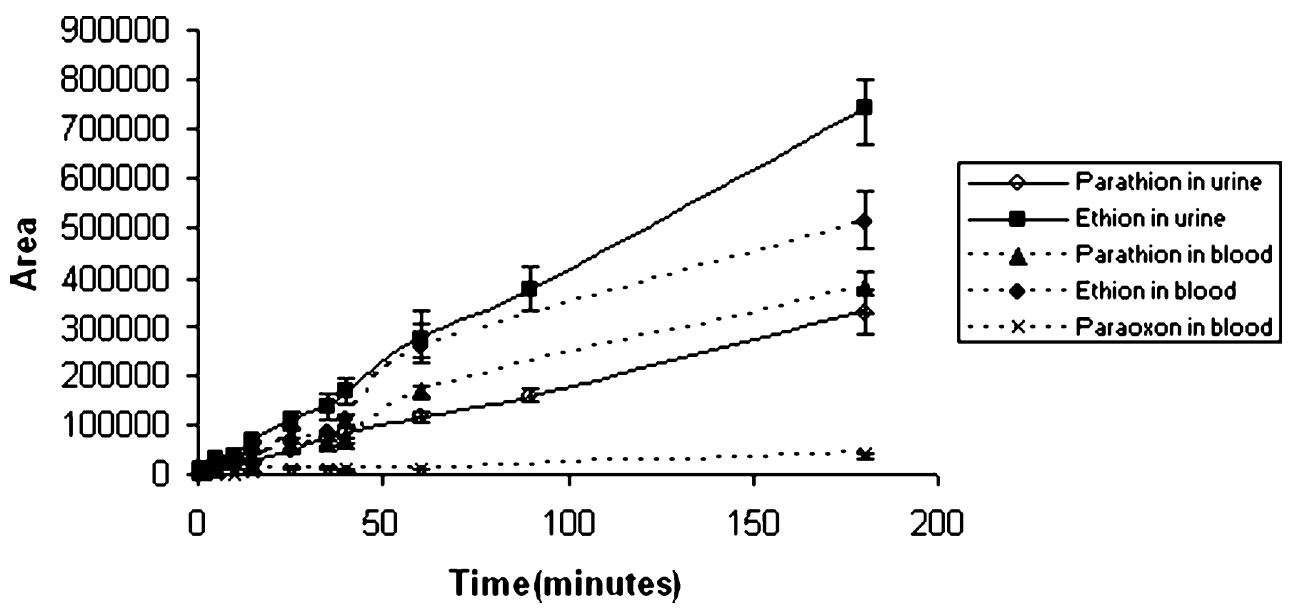


Fig. 2 Extraction yield of the analytes from urine (a) and blood (b) samples versus extraction temperature

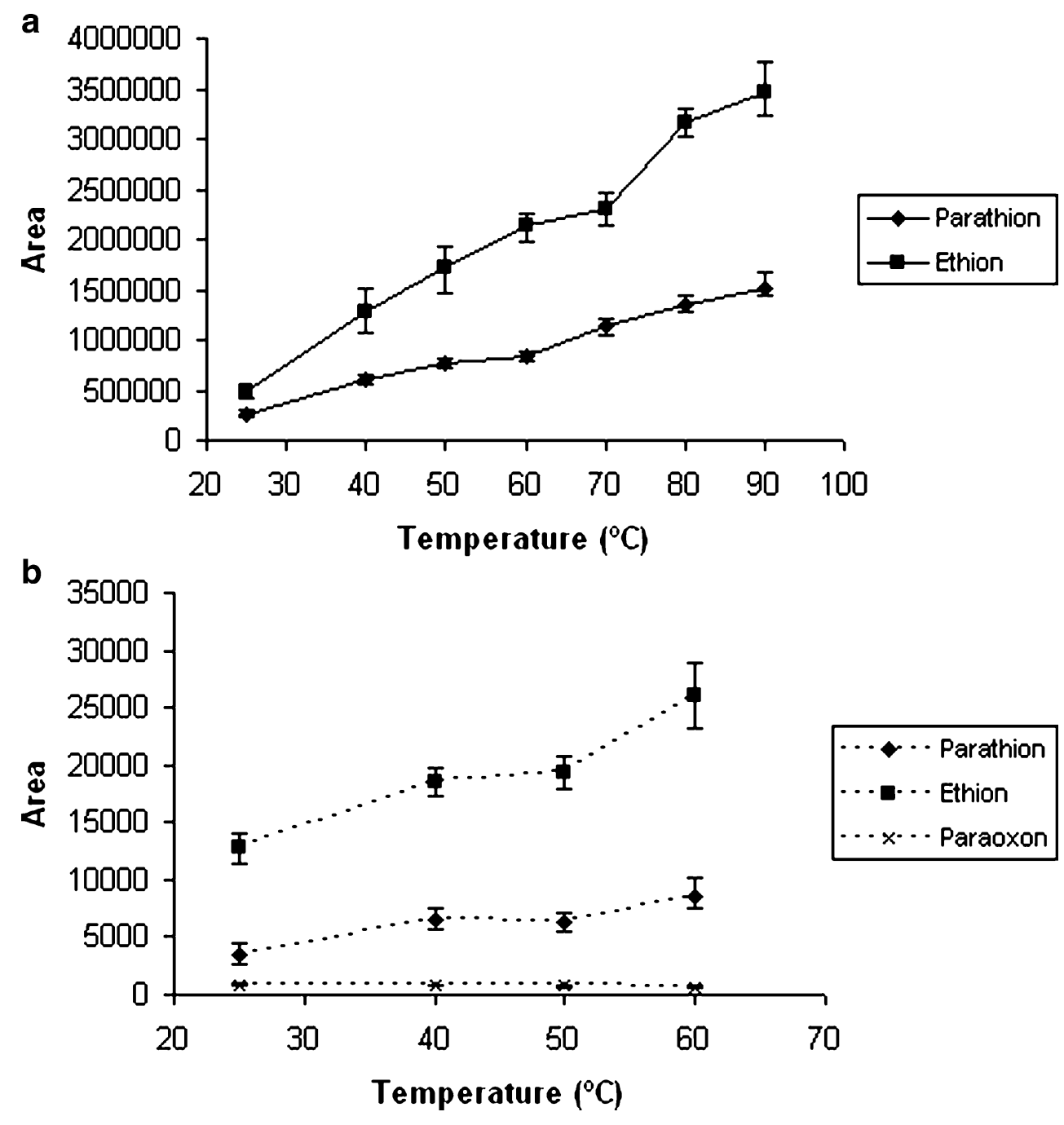

observed after the second desorption, which excluded the carry-over of analytes.

The temperature effect on the extraction yield was evaluated by varying the temperature between $25^{\circ} \mathrm{C}$ and $60{ }^{\circ} \mathrm{C}$ for blood, and between $25^{\circ} \mathrm{C}$ and $90{ }^{\circ} \mathrm{C}$ for urine samples. The extraction yield increased with the tempera- ture (Fig. 2) in both matrices, and therefore the selected temperatures were $60{ }^{\circ} \mathrm{C}$ for blood and $90{ }^{\circ} \mathrm{C}$ for urine. A 60 -min extraction of urine samples at $90{ }^{\circ} \mathrm{C}$ yielded 4 times more analyte than $180 \mathrm{~min}$ at room temperature.

Blood samples could not be heated above $60{ }^{\circ} \mathrm{C}$, because of coagulation (we experienced coagulation of the samples
Fig. 3 Effect of salt addition on the extraction yield

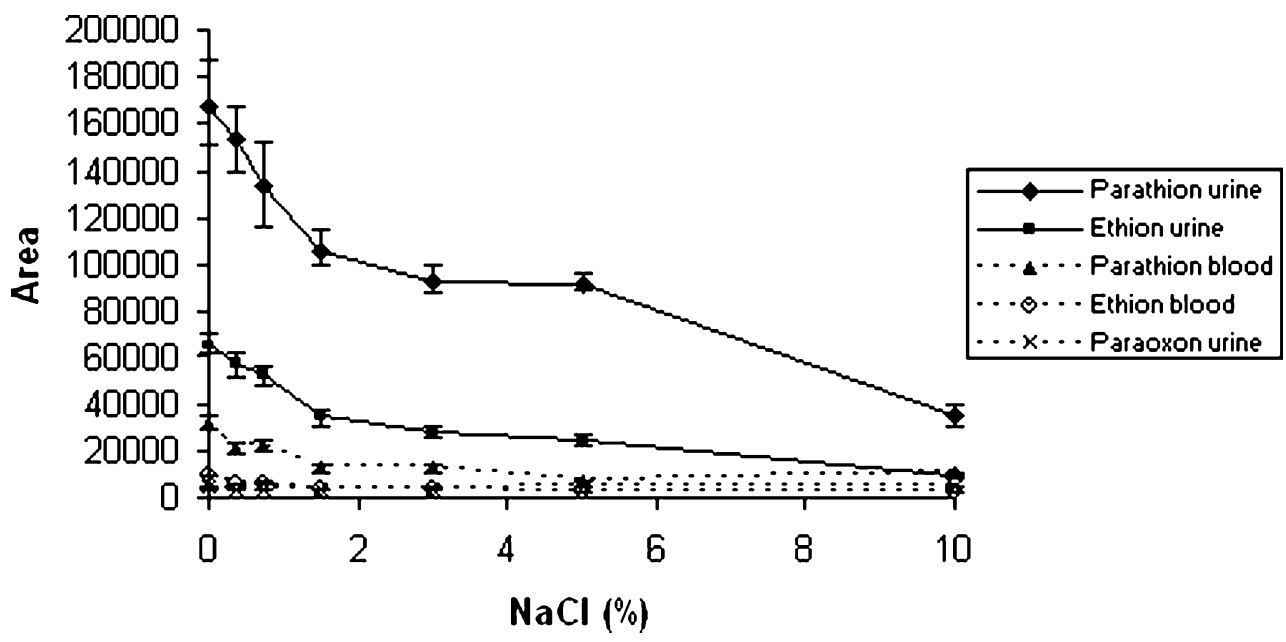


Fig. 4 Merged ion chromatograms of blood samples spiked with parathion at $0.05 \mu \mathrm{g} / \mathrm{mL}$ (a) and paraoxon at $1 \mu \mathrm{g} / \mathrm{mL}$ (b), and a urine sample spiked with parathion at $0.01 \mu \mathrm{g} / \mathrm{mL}$ (c), and from blank samples

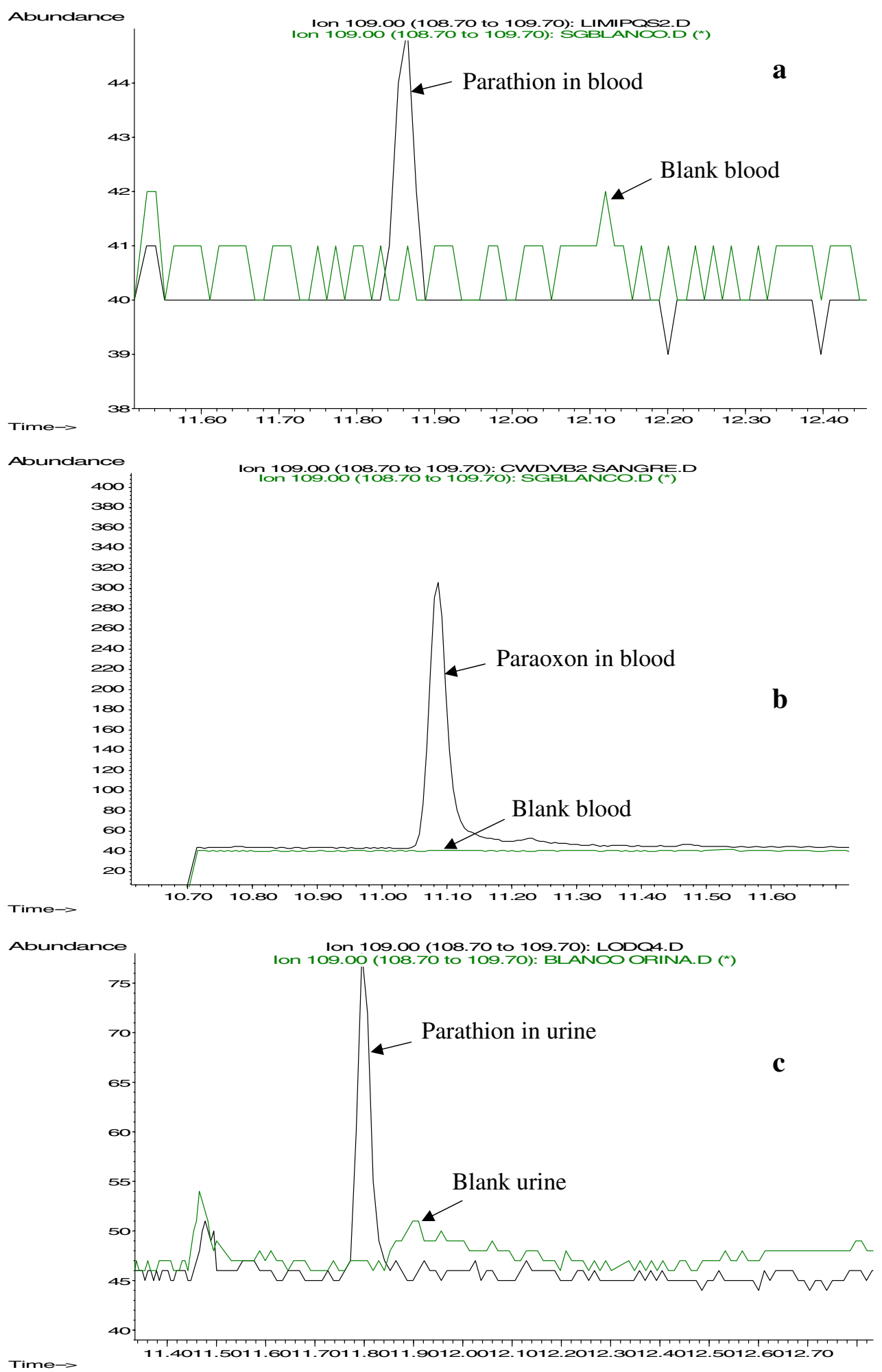

at $70{ }^{\circ} \mathrm{C}$ ), and a 60 -min extraction at this temperature yielded similar amounts of the analytes when compared to a 180-min extraction at room temperature.

In equilibrium, the temperature increase during extraction negatively affects the extraction recovery, because the distribution constant between the sample and the fibre coating decreases. However, under non-equilibrium conditions, it is possible to improve sensitivity by increasing the temperature at which the extraction is performed [30]. This fact may explain our results, since the time selected for 
Fig. 5 Merged ion chromatograms of parathion (ion 109) and chlorpyrifos (ion 97)

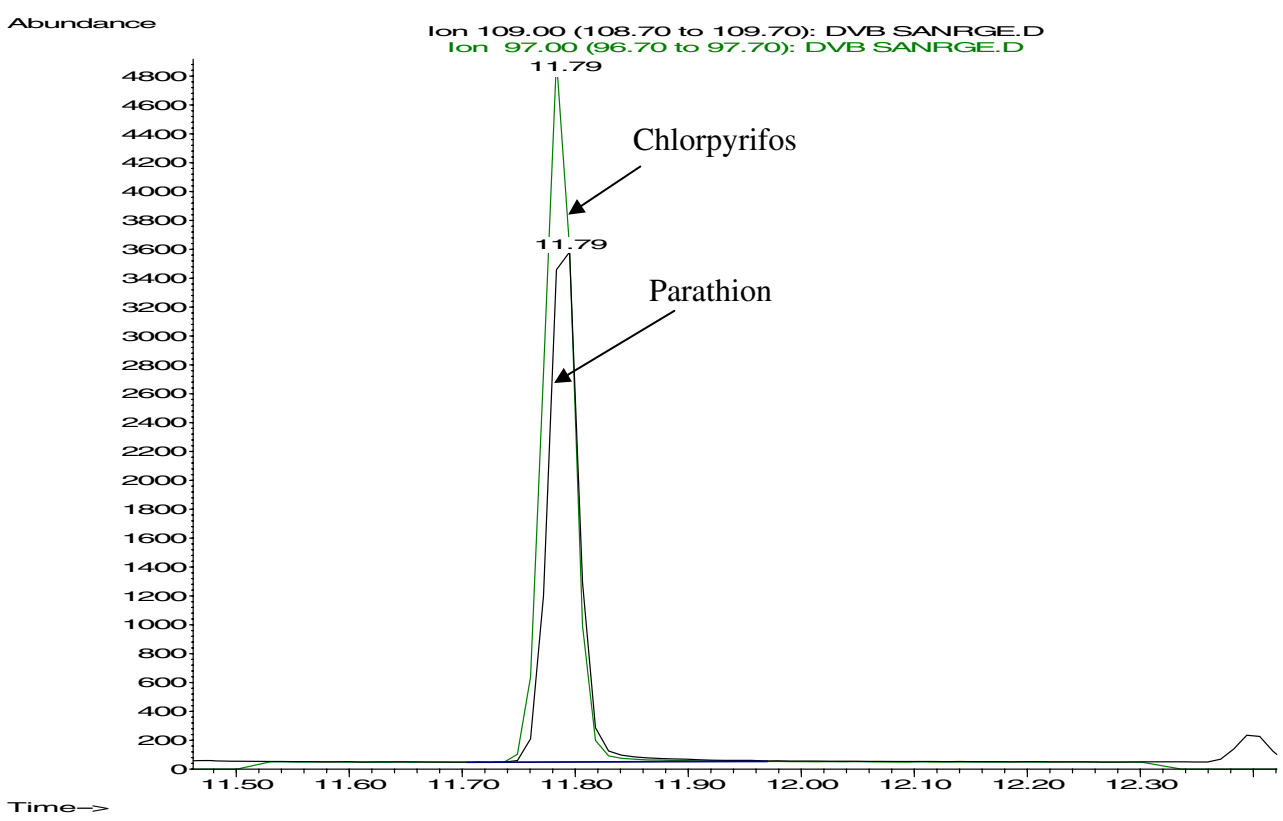

extraction was shorter than the equilibrium time (as above mentioned, equilibrium was not reached even after $180 \mathrm{~min})$.

To evaluate the influence of agitation on the extracted amount of parathion and paraoxon, blood and urine samples spiked at $1 \mu \mathrm{g} / \mathrm{mL}$ were analysed with and without agitation during the adsorption process, and peak areas were compared. Sample agitation did not significantly improve the extraction yield, and therefore it was decided not to agitate the samples during the extraction, as it would complicate the process.

The effect of $\mathrm{pH}$ on the extraction yield was evaluated by diluting blood and urine samples spiked with $1 \mu \mathrm{g} / \mathrm{mL}$ of each pesticide in phosphate buffer $0.07 \mathrm{M}(\mathrm{pH} \mathrm{5,6,7}$ and 8) instead of water. The peak areas obtained for each of the $\mathrm{pH}$ values were compared, and the highest peak areas were obtained at $\mathrm{pH}$ 8. However, the dilution of the sample with water yielded larger recovery of the analytes, which may have been due to an increase in salt concentration derived from the phosphate buffer. Therefore this study was carried out by diluting the sample with water.

Salt addition can improve the extraction yield as a result of a "salting out" effect. The effect of ionic strength on extraction efficiency was evaluated by analysing the amount of pesticides extracted in sample solutions containing $0,0.375,0.75,1.5,3,5$ and $10 \%$ sodium chloride.

Figure 3 illustrates the obtained results, and as can be seen the extracted amount diminished with the increase of salt concentration in the sample, which corroborates the results obtained in the $\mathrm{pH}$ experiments. Therefore this study was performed without salt addition.
Method validation

After optimization the methodology was validated according to internationally accepted criteria [31-33]. The studied parameters were selectivity, calibration curves, precision and accuracy, limits of detection and quantitation, recovery, dilution effect and stability.

The selectivity of the method was evaluated by analysis of ten blank blood and urine samples of different origin. The obtained chromatograms were compared with those obtained from blood and urine samples spiked with parathion and paraoxon (Fig. 4). The peaks were wellseparated and no interferences were observed. Furthermore, the interference of other substances that might eventually be present in the samples, such as other pesticides, was also evaluated, and could be excluded due to different retention times and/or mass spectra. For example, chlorpyrifos (an organophosphorous insecticide) has the same retention time of parathion. However, their mass spectra are different, and therefore it is possible to separate them, as can be seen in Fig. 5.

Linearity of the method for parathion was established on spiked blood and urine samples prepared and analysed using the described extraction procedures in the ranges of 0.05 to $50.00 \mu \mathrm{g} / \mathrm{mL}$ and 0.01 to $50.00 \mu \mathrm{g} / \mathrm{mL}$, respectively (ten calibrators each), each calibration level being analysed 6 times. The calibration curves were obtained by plotting the peak/area ratio between the analyte and ethion against analyte concentration. Calibration data is presented in Table 1. This parameter was only studied for parathion, since paraoxon was determined qualitatively.

The calibrators' accuracy, i.e. mean relative error (bias) between measured and spiked concentrations, was consid- 
Table 1 Linearity data

\begin{tabular}{|c|c|c|c|c|}
\hline \multirow[t]{2}{*}{ Sample } & \multirow{2}{*}{$\begin{array}{l}\text { Calibration } \\
\text { range }(\mu \mathrm{g} / \mathrm{mL})\end{array}$} & \multicolumn{2}{|c|}{ Linearity $(n=7)$} & \multirow{2}{*}{$\begin{array}{l}R^{2} \\
\text { values }^{\mathrm{a}}\end{array}$} \\
\hline & & Slope $^{a}$ & Intercept $\mathrm{t}^{\mathrm{a}}$ & \\
\hline \multirow[t]{2}{*}{ Blood } & $0.05-5.00$ & $\begin{array}{c}0.0507 \pm \\
0.0039\end{array}$ & $0.0010 \pm 0.0001$ & $\begin{array}{c}0.9999 \pm \\
0.0092\end{array}$ \\
\hline & $5.00-50.0$ & $\begin{array}{c}0.0898 \pm \\
0.0093\end{array}$ & $0.1825 \pm 0.0057$ & $\begin{array}{c}0.9982 \pm \\
0.0055\end{array}$ \\
\hline \multirow[t]{2}{*}{ Urine } & $0.01-1.00$ & $\begin{array}{c}0.0180 \pm \\
0.0006\end{array}$ & $7 \times 10^{-5} \pm 5.7 \times 10^{-6}$ & $\begin{array}{c}0.9954 \pm \\
0.0009\end{array}$ \\
\hline & $1.00-50.0$ & $\begin{array}{c}0.0264 \pm \\
0.0021\end{array}$ & $0.0790 \pm 0.0025$ & $\begin{array}{c}0.9980 \pm \\
0.0015\end{array}$ \\
\hline
\end{tabular}

${ }^{a}$ Mean value and standard error

ered adequate, being within $\pm 15 \%$ of the nominal concentration for all concentration levels, except for the lower limit of quantitation (LLOQ), for which 20\% was considered acceptable [31, 32].

The limit of quantitation (LOQ) was defined as the lowest parathion concentration that could be measured with adequate precision (coefficient of variation of less than $20 \%$ ) and accuracy (within $\pm 20 \%$ of the nominal concentration), and was found to be $10 \mathrm{ng} / \mathrm{mL}$ for urine and $50 \mathrm{ng} / \mathrm{mL}$ for blood. The limits of detection (LOD), defined as the lowest tested concentration yielding a signal-to-noise ratio higher than 3 , were 25 and $3 \mathrm{ng} / \mathrm{mL}$ for parathion in blood and urine respectively, and $50 \mathrm{ng} / \mathrm{mL}$ for paraoxon in blood. LOD of paraoxon in urine was not determined because as stated above this metabolite is rapidly hydrolysed [5]. These limits were close to the published values for parathion determination in blood by means of SPME [24-26], and were obtained using a smaller sample volume $(100 \mu \mathrm{L}$ versus 300 and $500 \mu \mathrm{L}$ ). The determination of parathion in urine has not yet been published in the literature, so we cannot compare our results.

Intraday precision and accuracy were evaluated by analysing in the same day 6 replicates of blank urine samples spiked with parathion at LOQ, 0.25, 2.50, 10.0, 25.0 and $50.0 \mu \mathrm{g} / \mathrm{mL}$ for blood, and at LOQ, 0.05, 0.10, $0.50,2.50,10.0$ and $50 \mu \mathrm{g} / \mathrm{mL}$ for urine. Interday precision and accuracy were determined at the same concentration levels over a period of 5 months. The values of intra- and interday precision in both matrices were less than $13 \%$, and the measured concentrations did not deviate more than $12 \%$ from the nominal concentration (Table 2).

Absolute recoveries of parathion were determined at 0.5, 5.0 and $25.0 \mu \mathrm{g} / \mathrm{mL}$ in urine and blood. For each concentration, 6 blank samples were spiked with parathion and analysed using the abovementioned procedures. The obtained peak areas were compared with those obtained from a splitless injection of $1 \mu \mathrm{L}$ methanolic solutions containing the same amount of the analyte. The mean calculated values were $35.1 \%$ for urine and $6.7 \%$ for blood. These recovery values are higher than the published values for the determination of parathion in blood samples using SPME $[24,26]$. We believe that the high temperature at which the extractions were performed contributed to the higher recoveries observed. However, these values are quite low when compared with the recovery values normally observed in other analytical methods (liquid-liquid extraction or solid-phase extraction). This is explained by the fact that SPME is an equilibrium process, rather than exhaustive. However, in this technique all the extracted amount of analyte is injected into the chromatographic system, unlike

Table 2 Precision, accuracy and recovery for the determination of parathion in blood and urine samples $(n=6)$

\begin{tabular}{|c|c|c|c|c|c|c|c|c|c|}
\hline \multirow[t]{2}{*}{ Sample } & \multirow{2}{*}{$\begin{array}{l}\text { Concentration } \\
(\mu \mathrm{g} / \mathrm{mL})\end{array}$} & \multirow{2}{*}{$\begin{array}{l}\text { Recovery } \\
(\%)\end{array}$} & \multirow{2}{*}{$\begin{array}{l}\text { Concentration } \\
(\mu \mathrm{g} / \mathrm{mL})\end{array}$} & \multicolumn{3}{|l|}{ Intraday precision } & \multicolumn{3}{|l|}{ Interday precision } \\
\hline & & & & $\begin{array}{l}\text { Concentration mean } \\
(\mu \mathrm{g} / \mathrm{mL})\end{array}$ & $\begin{array}{l}\mathrm{CV}^{\mathrm{a}} \\
(\%)\end{array}$ & $\begin{array}{l}\operatorname{Bias}^{\mathrm{b}} \\
(\%)\end{array}$ & $\begin{array}{l}\text { Concentration mean } \\
(\mu \mathrm{g} / \mathrm{mL})\end{array}$ & $\begin{array}{l}\mathrm{CV}^{\mathrm{a}} \\
(\%)\end{array}$ & $\begin{array}{l}\operatorname{Bias}^{\mathrm{b}} \\
(\%)\end{array}$ \\
\hline \multirow[t]{6}{*}{ Blood } & \multirow[t]{2}{*}{0.50} & \multirow[t]{2}{*}{6.7} & 0.05 & 0.05 & 6.23 & 8.15 & 0.05 & 9.24 & -9.79 \\
\hline & & & 0.25 & 0.25 & 1.75 & 1.87 & 0.26 & 1.21 & 2.41 \\
\hline & \multirow[t]{2}{*}{5.0} & \multirow[t]{2}{*}{6.6} & 2.50 & 2.32 & 1.82 & -7.27 & 2.42 & 5.67 & -3.33 \\
\hline & & & 10.0 & 9.65 & 2.98 & -3.50 & 9.08 & 4.69 & -9.16 \\
\hline & \multirow[t]{2}{*}{25.0} & \multirow[t]{2}{*}{6.7} & 25.0 & 26.80 & 3.20 & 7.20 & 27.89 & 6.34 & 11.59 \\
\hline & & & 50.0 & 52.08 & 1.04 & 4.17 & 46.26 & 5.03 & -7.47 \\
\hline \multirow[t]{7}{*}{ Urine } & \multirow[t]{3}{*}{0.50} & \multirow[t]{3}{*}{45.6} & 0.01 & 0.01 & 5.79 & -8.65 & 0.01 & 5.68 & 5.41 \\
\hline & & & 0.05 & 0.05 & 3.31 & 6.58 & 0.04 & 12.60 & -9.36 \\
\hline & & & 0.10 & 0.09 & 3.35 & -3.36 & 0.09 & 9.79 & -8.20 \\
\hline & \multirow[t]{2}{*}{5.0} & \multirow[t]{2}{*}{37.6} & 0.50 & 0.50 & 4.65 & -0.33 & 0.54 & 6.91 & 7.82 \\
\hline & & & 2.50 & 2.43 & 1.78 & -6.21 & 2.43 & 2.96 & -2.65 \\
\hline & \multirow[t]{2}{*}{25.0} & \multirow[t]{2}{*}{21.9} & 10.0 & 10.05 & 3.97 & 4.86 & 9.97 & 5.94 & -0.28 \\
\hline & & & 50.0 & 51.91 & 6.02 & 3.82 & 47.92 & 6.60 & -4.15 \\
\hline
\end{tabular}

\footnotetext{
${ }^{a} \mathrm{CV}$ coefficient of variation

${ }^{b}$ Bias $[($ measured concentration-nominal concentration)/nominal concentration] $\times 100$
} 
other extraction techniques, in which the extracts must be evaporated and reconstituted in a solvent, from which only a small aliquot is injected into the system. On the other hand, SPME is a highly selective technique, and the obtained chromatograms are in general cleaner than those obtained with other extraction methods. In this way, it is possible to detect and quantitate small amounts of the compounds, in spite of the low recovery observed.

The validation of a partial sample volume was done by spiking blood and urine samples with concentrations above the higher level of calibration. Five replicates of each sample were analysed after appropriate dilution with blank matrix to the validated concentration range (dilution factors of 2, 4 and 10). The calculated concentrations of these diluted samples, after multiplication by their respective dilution factors, showed a precision of less than $10 \%$ for blood and 13\% for urine samples.

In order to study stability in processed samples at two concentration levels, blood and urine were spiked with 0.25 and $10 \mu \mathrm{g} / \mathrm{mL}$ of parathion, and extracted using the abovementioned procedures $(n=3)$. However, after extraction the fibre was retracted, but it was not desorbed immediately in the GC injector. Instead, the fibre was left standing at room temperature for controlled time intervals $(5,10,15,20$ and $30 \mathrm{~min})$ before desorption. The measured concentrations for each tested time did not deviate more than $10 \%$ from the nominal concentration, and therefore the analyte is stable on the fibre coating for at least $30 \mathrm{~min}$ at room temperature.

Short-term stability was evaluated at the same concentration levels $(n=3)$. Blood and urine were spiked and these samples were left at room temperature for $24 \mathrm{~h}$. These samples were compared with samples prepared and analysed in the same day, and the obtained values for precision were less than $4 \%$ for blood and $13 \%$ for urine samples.

Freeze and thaw stability was also evaluated in triplicate at two concentration levels. Blood and urine samples were spiked with 0.25 and $10 \mu \mathrm{g} / \mathrm{mL}$ of parathion, and these aliquots were stored at the intended storage temperature for $24 \mathrm{~h}$, after which they were thawed unassisted at room temperature. When completely thawed, the samples were re-frozen for $12-24 \mathrm{~h}$ under the same conditions. This freeze/thaw cycle was repeated twice more, and the samples were analysed after the third cycle. These samples were compared to samples prepared and analysed in the same day, and the analytes were stable for at least 3 freeze/thaw cycles (the measured concentrations did not deviate more than $11 \%$ from the nominal concentration for both matrices).

To demonstrate the applicability of this procedure, samples proceeding from 25 cases of acute intoxication were analysed and the obtained results are presented in Table 3 . The compound was identified by its retention time and by the relative amounts of the selected ions. A typical chromatogram of a blood sample is shown in Fig. 6.

Parathion is the second most detected pesticide in acute organophosphorous intoxications (mainly suicides) in Portugal, in spite of the fact that its commercialization has been prohibited since 1995, which indicates that people have stored it, particularly in rural areas. The high levels detected in some of the samples are consistent with the route of administration normally seen in these cases, in which people tend to ingest large amounts of the pesticide. On the other hand, there is the possibility of contamination during autopsy procedures, as well as post-mortem redistribution phenomena.

Concerning paraoxon, it was not detected in any of the analysed samples. We believe that the SPME method was not responsible for not detecting this compound, since it was optimized, and a low limit of detection was obtained. It is possible that this compound was not detected because of its lack of stability in the frozen samples, which was not studied. Furthermore, the conservation conditions of the samples between their collection at autopsy and the arrival at the laboratory are not known.

Table 3 Results obtained by applying the method to 25 real samples

\begin{tabular}{|c|c|c|}
\hline \multirow[t]{2}{*}{ Case } & \multicolumn{2}{|c|}{ Concentration $(\mu \mathrm{g} / \mathrm{mL})$} \\
\hline & Blood & Urine \\
\hline 1 & $>500$ & n.a. \\
\hline 2 & 0.07 & $<\mathrm{LOQ}$ \\
\hline 3 & 482.52 & n.a. \\
\hline 4 & 243.11 & n.a. \\
\hline 5 & 2.07 & n.a. \\
\hline 6 & 0.24 & n.a. \\
\hline 7 & 18.85 & 0.05 \\
\hline 8 & $>500$ & n.a. \\
\hline 9 & $>500$ & n.a. \\
\hline 10 & 3.43 & n.a. \\
\hline 11 & $>500$ & n.a. \\
\hline 12 & 1.26 & n.a. \\
\hline 13 & 0.58 & n.a. \\
\hline 14 & 0.66 & n.a. \\
\hline 15 & 0.33 & n.a. \\
\hline 16 & 1.44 & 4.76 \\
\hline 17 & 0.30 & n.a. \\
\hline 18 & 1.52 & n.a. \\
\hline 19 & $<$ LOQ & n.a. \\
\hline 20 & 18.44 & n.a. \\
\hline 21 & $<$ LOQ & $<\mathrm{LOD}$ \\
\hline 22 & 1.26 & n.a. \\
\hline 23 & 11.17 & n.a. \\
\hline 24 & 1.02 & n.a. \\
\hline 25 & 30.24 & $<\mathrm{LOQ}$ \\
\hline
\end{tabular}

n.a. sample not available 
Fig. 6 Chromatogram from a real blood sample (case 7: $18.85 \mu \mathrm{g} / \mathrm{mL}$ )

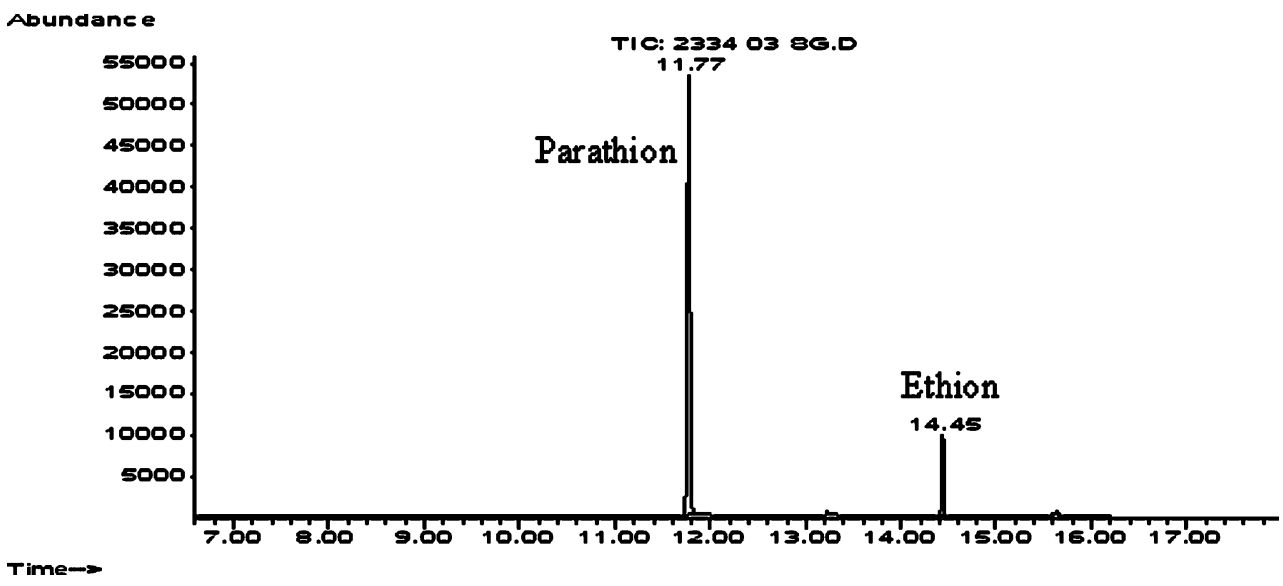

Concerning the urine samples, in most of the cases this sample was not available, since in most post-mortem situations the pathologist does not send urine samples for analysis. Therefore, only 5 urine samples could be analysed.

\section{Conclusions}

We have developed a simple and rapid method for the quantitation of parathion in blood and urine using DI-SPME. The procedure is sensitive and specific, presenting low limits of detection and quantitation, and moreover requires only $100 \mu \mathrm{L}$ of sample. In this technique no organic solvent is required to accomplish the analysis, which is important from an environmental standpoint, since waste disposal is avoided. There is no need to evaporate and reconstitute the extracts, and therefore this methodology may be an alternative to the more time-consuming extraction methods, like liquid-liquid or solid-phase extraction, for the determination of this organophosphorous insecticide in biological media, both in clinical and forensic toxicology.

\section{References}

1. World Health Organization and Food and Agriculture Organization. Data sheets on pesticides. INCHEM [document online] [cited 26th Jun 2006]. Available from URL: http://www.inchem.org/ documents/pds/pds/pest6_e.htm

2. Tomlin CDS (ed) (1997) The pesticide manual, 11th edn. British Crop Protection Council, Surrey, p 926

3. Kała M (2004) Pesticides. In: Moffat AC, Osselton MD, Widdop B (eds) Clarke's analysis of drugs and poisons, 3rd edn. Pharmaceutical Press, London, pp 202-226

4. Taylor P (1996) Anticholinesterase agents. In: Hardman JG, Limbird LE (eds) Goodman \& Gilman's the pharmacological basis of therapeutics, 9th edn. McGraw Hill, New York, pp 161176

5. Baselt RC (2004) Disposition of toxic drugs and chemicals in man, 7th edn. Biomedical Publications, Foster City, p 846-848

6. Uges DRA. The International Association of Forensic Toxicologists (TIAFT): Therapeutic and toxic drug concentrations list. [document online] [cited 26th Jun 2006]. Available from URL: http://www.tiaft.org/tmembers/ttv/ttv_ps.html

7. Tewari SN, Ram L (1970) Mikrochim Acta 58-60

8. Ferrer C, Gómez MJ, Garcia-Reyes JF, Ferrer I, Thurman EM, Fernández-Alba AR (2005) J Chromatogr A 1069:183-194

9. Padrin-Sanz C, Halko R, Sosa-Ferrera Z, Santana-Rodriguez JJ (2005) J Chromatogr A 1078:13-21

10. Abbas R, Hayton WL (1996) J Anal Toxicol 20:151-154

11. Arthur CL, Pawliszyn J (1990) Anal Chem 62:2145-2148

12. Beltrán J, López FJ, Hernández F (2000) J Chromatogr A 885:389-404

13. Lambropoulou DA, Sakkas VA, Albanis TA (2002) Anal Bional Chem 374:932-941

14. Sng MT, Lee FK, Lakso HÅ (1997) J Chromatogr A 759:225-230

15. Gonzalez-Rodriguez MJ, Arrebola Liebanas FJ, Garrido Frenich A, Martinez Vidal JL, Sanchez-Lopez FJ (2005) Anal Bional Chem 382:164-172

16. Beltrán J, Peruga A, Pitchard E, López FJ, Hernández F (2003) Anal Bional Chem 376:502-511

17. Fernández M, Padrón C, Marconi L, Ghini S, Colombo R, Sabatini AG, Girotti S (2001) J Chromatogr A 922:257-265

18. Gallardo E, Barroso M, Margalho C, Cruz A, Vieira DN, LópezRivadulla M (2006) Rapid Commun Mass Spectrom 20:865-869

19. Gallardo E, Barroso M, Margalho C, Cruz A, Vieira DN, LópezRivadulla M (2006) J Chromatogr B 832:162-168

20. López FJ, Pitarch E, Egea S, Beltrán J, Hernández F (2001) Anal Chim Acta 433:217-226

21. Namera A, Yashiki M, Nagasawa N, Iwasaki Y, Kojima T (1997) Forensic Sci Int 88:125-131

22. Tsoukali H, Raikos N, Theodoridis G, Psaroulis D (2004) Forensic Sci Int 143:127-132

23. Hernández F, Pitchard E, Beltrán J, López FJ (2002) J Chromatogr B 769:65-77

24. Tsoukali H, Theodoridis G, Raikos N, Grigoratou I (2005) J Chromatogr B 822:194-200

25. Musshoff F, Junker H, Madea B (1999) Clin Chem Lab Med 37:639-642

26. Musshoff F, Junker H, Madea B (2002) J Chromatogr Sci 40:29-34

27. Dien K, Lentner C (1975) Tablas científicas. Ciba Geigy, Basel 
28. Pawliszyn J (1997) Solid phase microextraction. Wiley-VCH, New York

29. Barroso M, Gallardo E, Margalho C, Ávila S, Marques EP, Vieira DN, López-Rivadulla M (2005) J Chromatogr B 816:29-34

30. Ulrich S (2001) J Chromatogr A 902:167-194

31. Food and Drug Administration: US Department of Health and Human Services, guidance for industry, bioanalytical method validation. FDA [document online] [cited 26th Jun 2006]. Available from URL: http://www.fda.gov/cder/guidance/4252fnl.pdf

32. International conference on harmonization $(\mathrm{ICH})$, validation of analytical procedures: methodology ICH Q2 B. ICH [document online] [cited 26th Jun 2006]. Available from URL: http://www. ich.org/MediaServer.jser?@_ID=4188@_MODE=GLB

33. Peters FT, Maurer HH (2002) Accredit Qual Assur 7:441-449 